\title{
Primitive Node
}

National Cancer Institute

\section{Source}

National Cancer Institute. Primitive Node. NCI Thesaurus. Code C34266.

The small circular, localized expansion of the cranial end of the primitive streak, which is centered around the primitive pit, and is where gastrulation takes place. 